\title{
Outbreak Information Delivery to Families with (Pre)School Children and Its Contribution
}

\author{
Tamie Sugawara1 $^{*}$, Yasushi Ohkusa1, Michiko Nohora² \\ ${ }^{1}$ National Institute of Infectious Diseases, Tokyo, Japan \\ ${ }^{2}$ Tokyo Kasei University, Tokyo, Japan \\ Email: ^tammy@nih.go.jp
}

How to cite this paper: Sugawara, T., Ohkusa, Y. and Nohora, M. (2019) Outbreak Information Delivery to Families with (Pre)School Children and Its Contribution. Journal of Biosciences and Medicines, 7 , $31-43$.

https://doi.org/10.4236/jbm.2019.712004

Received: October 21, 2019

Accepted: November 28, 2019

Published: December 2, 2019

Copyright $\odot 2019$ by author(s) and Scientific Research Publishing Inc. This work is licensed under the Creative Commons Attribution International License (CC BY 4.0).

http://creativecommons.org/licenses/by/4.0/

\begin{abstract}
Background: Infection transmission among them occurs easily and sometimes causes outbreaks at facilities where children live in groups. Early response is necessary for infection control measures to avoid larger clusters. In Japan, (Nursery) School Absenteeism Surveillance System ((N)SASSy), which is a kind of school absenteeism surveillance, has activated since 2007 and covers about $60 \%$ of all schools and $40 \%$ of all nursery schools in 2017 . Objective: The objective of the present paper is investigation and demonstration of how caregivers receive information related to infectious diseases in Japan and how (N)SASSy contributes health of children. Method: We randomly selected subjects with children by prefecture in October, 2017. The survey questionnaire asked background information and information about infectious diseases to maintain health in children. We regressed health concern variables on background information and information provision situation about community outbreaks using weighted logistic regression. Results: We received responses from 1172 people. Estimation results showed higher concern about a facility providing information about community outbreak. Caregivers whose children attend facilities provided about community outbreak or covered (N)SASSy significantly higher opportunity to arrange a schedule when a child has a high fever. Discussion: The obtained results demonstrated that activation in (N)SASSy affects the possibility of arranging a schedule when a child has a high fever. This capability might improve community health.
\end{abstract}

\section{Keywords}

School Absenteeism Surveillance, Outbreak Information, Families with (Pre)School Children, Nursery School, Infection Control 


\section{Introduction}

Because children live in groups in nursery schools, kindergartens, schools, and kodomoen (a hybrid facility of nursery school and kindergarten), infection transmission among them occurs easily and sometimes causes outbreaks. Hereafter, the term "(nursery) school" denotes both a nursery school and schools including kindergartens, kodomoen, elementary schools, junior high schools, and high schools. Early response is necessary for infection control measures to avoid larger clusters, prevent complicated cases, and subsequently minimize health damage deriving from an outbreak.

Actually, because caregivers with preschool children have great concern about sudden onset and infectious diseases among children, they eagerly seek information related to outbreak or infectious diseases [1] [2] [3]. If they can receive such information, caregivers use the information to take precautions at home and to rearrange working schedules if they are working.

Regarding earlier response, earlier detection is necessary to find indications of outbreak and then switch the daily modes of activity from usual hygiene to infection control measures. Particularly, surveillance of prescriptions and absenteeism from (nursery) school have been used routinely nationwide and used by local government, public health centers, (nursery) schools or medical institutions. Information about absenteeism from (nursery) school has been integrated and systematized into the (Nursery) School Absenteeism Surveillance System ((N)SASSy) [4]-[12].

Many surveillance efforts conducted worldwide have assessed school absenteeism [13]-[20]. However, they all monitored absenteeism or only those related to influenza. In Japan, by contrast, all reasons for absence from (nursery) schools related to illness, symptoms, and diagnosed diseases are reported to (nursery) schools. (N)SASSy used this virtue as systematic information sharing to monitor all symptoms and diagnosed diseases. Public health authorities and medical professionals have used this system to control the spread of infectious disease [11]. Moreover, an evidence demonstrates that (N)SASSy can reduce the number of patients with some infectious diseases [12].

Caregivers of students who are absent from (nursery) school because of infectious diseases usually report to (nursery) school. School nurses and other teachers provide information to (N)SASSy through the internet. As of the end of 2016, the system encompassed approximately 37,000 schools, including 10,000 nursery schools, or about $60 \%$ of all schools and $40 \%$ of all nursery schools in Japan. On a daily basis, it monitors the health conditions of about four million children younger than 18 years old. The information in (N)SASSy is used in (nursery) schools themselves to recognize the situation of the surrounding areas and inform teachers, students, and caregivers, thereby promoting precaution if some outbreak is found in surrounding areas but not at their own (nursery) school. Information in (N)SASSy is also shared between (nursery) school doctors, the educational board, the local government offices for nursery schools, the 
public health center, and the local medical association. The shared information encourages earlier awareness of infectious diseases, which engenders earlier response to the initial stage of outbreaks in (nursery) schools. Moreover, having such a large trove of data related to children's health promotes large epidemiological studies. Currently, it is conducted by the Japanese Society of School Health.

In terms of public health, Japan's school system is unique. According to the School Health and Safety Act, at all levels of schools except for nursery schools, when students are diagnosed with certain designated infectious diseases such as influenza, varicella, and mumps, schools must not allow students to attend classes. We designate it as "attendance prohibition due to infectious disease". A student who has a defined infectious disease cannot attend classes, but the lack of attendance does not count as an absence. Caregivers must notify the school if their children are diagnosed with a defined infectious disease. Moreover, even if the children have not visited a doctor or have not been diagnosed with any defined disease, caregivers usually call the school and report a child's symptoms, e.g., fever, vomiting, or diarrhea. In these cases, schools do not apply "attendance prohibition due to infectious disease". No other country has a similar system.

Nursery schools, by contrast, are not classified as education institutions but as welfare facilities. Therefore, the School Health and Safety Act is not applied to nursery school children. They do not fall under "attendance prohibition due to infectious diseases" even if diagnosed with a defined infectious disease. Even if such a disease is not diagnosed or the child did not visit a doctor, nursery school caregivers also usually report a child's health condition to the nursery school. Of course, the law requires no action, but almost all nursery schools require caregivers to give a report based on the guideline from the Ministry of Health, Labour, and Welfare. Additionally, the culture, custom, or rule among schoolchildren's caregivers might affect caregiver behavior because nursery school children might be younger siblings of schoolchildren within a family.

In short, all information related to children's health conditions is integrated in (nursery) schools. (N)SASSy maintains a computerized system comprising such information and network of information sharing among the concerned organizations and individuals. Consequently, (N)SASSy can be used as a form of syndromic surveillance in Japan. It can be a powerful public health tool for use during mass gatherings or important political events [4] such as a G7 summit meeting. In fact, it is intended for use during the 2020 Tokyo Olympic Games. It was also used at school nurse workshops. Public health sector and (nursery) schools have been using (N)SASSy.

Nevertheless, for security reasons, caregivers who need outbreak information [1] cannot access (N)SASSy directly, even though they receive information from (N)SASSy through (nursery) schools. Consequently, the objective of the present paper is investigation and demonstration of how caregivers receive information related to infectious diseases in Japan. This might be the first report of the rele- 
vant literature describing an examination revealing the current status of caregivers receiving information of infectious diseases.

\section{Method and Materials}

We randomly selected subjects with children by prefecture in October, 2017 from a list of household which registered to corporate internet survey and has children. This list was provided by an internet survey company. In the survey questionnaire, we elicited background information such as prefecture, age, gender, marriage status, number of children, job status, job status of partner, type of facility the youngest child attends, use of public or private facilities, facility location, and usual information-seeking activities using a smartphone. Moreover, we solicited information about infectious diseases to maintain health in children such as concerns about outbreaks at facilities the children attend, concern about child health conditions, provision of information related to infectious diseases in the facility from the facility, provision of information of infectious diseases in the community from the facility, children's immunization record, whether it is possible to arrange a schedule when a child has a high fever, and concerns about some students in the class in which the child attend showed illness. No personal information for identification in the data was included in this survey. The survey was conducted in October, 2017 and its duration was one week. The survey area was nationwide in Japan. Questionnaire design was similar with the previous studies [2] [3] principally, but it was extended to include the area where (N)SASSy have not been activated so as to evaluate effectiveness of (N)SASSy.

Analysis examined the association among necessarily infectious diseases or health maintenance of children from the survey and activation in (N)SASSy. The activation status of (N)SASSy was classified to two classifications as the facility youngest child attend was covered (N)SASSy. It was activated in (nursery) schools in their residential area. We denoted the former as (N)SASSy in the facility and the latter as (N)SASSy at all facilities.

The area was defined as the municipality. We define caregiver as respondents if the job status of respondents was "no". Conversely, if the job status of respondents was "yes" and job status of respondents' partner was "no", we defined the caregiver as the respondent's spouse. If a respondent was single, or if both the respondent and the spouse worked outside or did not work, then we defined the caregiver as the respondent.

We regressed health concern variables on caregiver age, youngest child age, more than two children, job status of a caregiver, and information provision situation about community outbreaks using weighted logistic regression weighted by the population of the municipality of residence. We presumed five variables as health concern variables: "Are you concerned about outbreaks at the facility the children attend?", "Are you concerned about the health condition of the children?", "Child immunization record", "Are you concerned if your child's classmates show illness?" and "Can you change your schedule if your child has a 
high fever?" We assumed three variables as information providing situation about community outbreaks: "Information provision from the facility," (N)SASSy at the facility, and (N)SASSy at all facilities. As these three variables were supposed to be correlated to each other, we estimated three specifications including one of these three variables separately for each dependent variable.

These dummy variables take the following values: "Caregiver age" is one if the caregiver works outside the home; it is zero otherwise. "More than two children" is one if the family has more than two children; it is zero otherwise. "Job status" takes a value of one if the caregiver works outside home; it is zero otherwise. Also, "Information provision from the facility" takes a value of one if the attended facility provides information about infectious diseases to the community; it is zero otherwise. "(N)SASSy in the facility" is one if the attended facility has activated (N)SASSy; it is zero otherwise. "(N)SASSy at all facilities" is one if the facility located where (N)SASSy was activated in both of nursery schools and schools; it is zero otherwise. "Are you concerned about outbreaks at your child's facility?", "Are you concerned about your child's health condition?", "Are you concerned if your child's classmates show illness?" and "Can you change your schedule when your child has a high fever?" were one if answered as yes; they were zero otherwise. "Child's immunization record" was one if a caregiver kept immunization records; it was zero otherwise.

\section{Ethics}

The survey used for the present study includes only anonymous data that were de-linked from individual patient information with no private information such as a name, address or phone number. Therefore, ethical issues in Japan related to the medical science for humans (Ministry of Education, Culture, Sports, Science and Technology and Ministry of Health, Labour and Welfare (22 December, 2014, revised on 28 February 2017) were not applicable to this study. For that reason, no formal ethical review was warranted or required.

\section{Results}

We received responses from 1172 people. Table 1 presents their socio-demographical background. Responders were mainly in their $20 \mathrm{~s}$ or $40 \mathrm{~s}$; $99 \%$ were women. Marriage status revealed that $89.9 \%$ were married; $8.6 \%$ were divorced or widowed. Regarding the number of children, one child households were the highest, with $48.9 \%$, followed by two child households, with $38.6 \%$. The age of the youngest child was preschool child under five years old, accounting for $52.2 \%$, followed by elementary school child older than 6 but younger than 11 years old, with $35.4 \%$. Of respondents, $58.3 \%$ worked outside the home; $82.5 \%$ of respondent partners were working. The youngest children attended elementary school in $35.3 \%$ of households, followed by nursery school in $23.9 \%$. Of attended facilities, 55.3\% were public (nursery) schools; private were $34.8 \%$. Of them, $94.2 \%$ attend a facility in their same municipality. Of respondents, $71.5 \%$ collect information from a smart phone. 
Table 1. Summary statistics of respondents' socio-demographical characteristics.

\begin{tabular}{|c|c|c|c|}
\hline & & Number of respondents & Proportion (\%) \\
\hline \multirow[t]{4}{*}{ Caregiver age } & $20-29$ & 106 & 9.0 \\
\hline & $30-39$ & 572 & 48.8 \\
\hline & $40-49$ & 449 & 38.3 \\
\hline & $50-59$ & 45 & 3.8 \\
\hline \multirow[t]{2}{*}{ Caregiver gender } & male & 10 & 0.9 \\
\hline & female & 1162 & 99.1 \\
\hline \multirow[t]{3}{*}{ Marriage status } & married & 1054 & 89.9 \\
\hline & unmarried & 17 & 1.5 \\
\hline & divorce & 101 & 8.6 \\
\hline \multirow[t]{4}{*}{ Number of children } & one & 573 & 48.9 \\
\hline & two & 452 & 38.6 \\
\hline & three & 131 & 11.2 \\
\hline & more than four & 16 & 1.4 \\
\hline \multirow[t]{4}{*}{ Youngest child age } & 0 - 6 years old & 612 & 52.2 \\
\hline & 7 - 12 years old & 415 & 35.4 \\
\hline & 13 - 15 years old & 81 & 6.9 \\
\hline & 16 - 18 years old & 64 & 5.5 \\
\hline \multirow[t]{3}{*}{ Caregiver job status } & yes & 683 & 58.3 \\
\hline & no & 487 & 41.6 \\
\hline & unknown & 2 & 0.2 \\
\hline \multirow[t]{4}{*}{ Partner job status } & yes & 967 & 82.5 \\
\hline & no & 85 & 7.3 \\
\hline & unknown & 2 & 0.2 \\
\hline & unanswered & 118 & 10.1 \\
\hline \multirow[t]{7}{*}{ Youngest child attends } & nursery school & 280 & 23.9 \\
\hline & kodomoen & 99 & 8.4 \\
\hline & kindergarten & 234 & 20.0 \\
\hline & elementary school & 414 & 35.3 \\
\hline & junior high school & 54 & 4.6 \\
\hline & high school & 54 & 4.6 \\
\hline & others & 37 & 3.2 \\
\hline \multirow[t]{3}{*}{ Public or private facility? } & public & 648 & 55.3 \\
\hline & private & 408 & 34.8 \\
\hline & others & 116 & 9.9 \\
\hline \multirow{3}{*}{$\begin{array}{l}\text { Is the facility the youngest } \\
\text { child attends outside the } \\
\text { municipality of residence? }\end{array}$} & yes & 1104 & 94.2 \\
\hline & no & 68 & 5.8 \\
\hline & yes & 838 & 71.5 \\
\hline \multirow{3}{*}{$\begin{array}{l}\text { Usual information seeking } \\
\text { activity by smartphone }\end{array}$} & sometimes & 241 & 20.6 \\
\hline & no & 90 & 7.7 \\
\hline & unknown & 3 & 0.3 \\
\hline
\end{tabular}

Subjects were asked for background information such as prefecture of residence, age, gender, marriage status, number of children, job status, partner job status, type of facility youngest child attends, and public or private facility. 
Table 2 summarized health concern among respondents and situation of providing information about infectious diseases from community or (nursery) schools. Regarding information gathering of infectious diseases for health maintenance, $74.7 \%$ of respondents were concerned about the health condition of children, $73.2 \%$ were concerned about outbreak in the attended facilities, and $76.4 \%$ of them receive some information about infectious diseases from the attended facilities. The highest proportion of frequencies was "as needed" in $69.4 \%$, followed by "every day" in $11.8 \%$. The most common method to receive the information was mail from (nursery) schools, followed by e-mail and notices on a bulletin board.

Related to providing of information of infectious diseases in the community from the facility, 33.4\% of respondents received such information. However, $37.8 \%$ of respondents answered unknown. Of those received, the highest proportion of frequencies was "as needed", with $66.2 \%$, followed by "once a week" with $13.8 \%$. The most common method to receive such information was mail from (nursery) schools, which accounted for $42.7 \%$ of responses, followed by e-mail (37.1\%), and homepages (32.0\%). Moreover, $89.3 \%$ of those who received information answered that it was useful.

Though it was not shown in table, (N)SASSy had been activated in at least some (nursery) schools in $73 \%$ of respondents' residential areas. Both of (nursery) schools were activated in $20.3 \%$ of these areas, schools only in $39.8 \%$, nursery schools only in $4.6 \%$, part of (nursery) schools in $8.4 \%$.

Table 3 presents estimation results of health concern. It contains five dependent variable and three specifications for each dependent variables. Only but consistently caregiver's outside job significantly negative effect on "Are you concerned about outbreaks in the facility the children attend?" Younger caregivers have significantly less concern about a child's health condition only in cases of information provision situations about community outbreak as "information provision from the facility." Caregivers were found to have a significant tendency to keep child immunization records if the facility provided information about community outbreaks. If a family has more than two children, then caregivers have significantly greater concern about the class situation in the same class. They also report significantly higher concern about a facility providing information about community outbreak. Caregivers whose children attend facilities provided about community outbreak or covered (N)SASSy significantly higher opportunity to arrange a schedule when a child has a high fever.

\section{Discussion}

This study examines at first time to approach the situation at caregivers from the survey rather than how public health section [11] or (nursery) schools use (N)SASSy. Older working caregivers with more than two children tend to have higher health concerns. Moreover, to attend the facility provided about community outbreak or covered (N)SASSy makes it easier to arrange the working schedule if a child had onset suddenly. That information about community 
Table 2. Summary statistics of health concern and situation of providing information about infectious diseases from community or (nursery) schools and.

\begin{tabular}{|c|c|c|c|}
\hline & & Number of respondents & Proportion (\%) \\
\hline \multirow{3}{*}{$\begin{array}{l}\text { Concern about outbreaks } \\
\text { at the facility the children attend }\end{array}$} & yes & 857 & 73.1 \\
\hline & no & 249 & 21.2 \\
\hline & unknown & 66 & 5.6 \\
\hline \multirow{3}{*}{$\begin{array}{l}\text { Concern about your } \\
\text { child's health condition }\end{array}$} & yes & 875 & 74.7 \\
\hline & no & 282 & 24.1 \\
\hline & unknown & 15 & 1.3 \\
\hline \multirow[t]{3}{*}{ Child immunization record } & yes & 1126 & 96.1 \\
\hline & no & 33 & 2.8 \\
\hline & unknown & 13 & 1.1 \\
\hline \multirow{3}{*}{$\begin{array}{l}\text { Concern about child's } \\
\text { classmates' illness }\end{array}$} & yes & 1101 & 93.9 \\
\hline & no & 47 & 4.0 \\
\hline & unknown & 24 & 2.0 \\
\hline \multirow{2}{*}{$\begin{array}{l}\text { Can you change your schedule } \\
\text { when your child has a high fever? }\end{array}$} & yes & 1080 & 92.2 \\
\hline & no & 92 & 7.8 \\
\hline \multirow{7}{*}{$\begin{array}{l}\text { If your child were diagnosed } \\
\text { as having influenza today, who } \\
\text { would care for sick child? } \\
\text { (Multiple answers allowed) }\end{array}$} & me & 1072 & 91.5 \\
\hline & family member except me & 146 & 12.5 \\
\hline & grandparent or other relations & 129 & 11.0 \\
\hline & babysitter & 6 & 0.5 \\
\hline & day care for sick children & 31 & 2.6 \\
\hline & others & 6 & 0.5 \\
\hline & do nothing & 10 & 0.9 \\
\hline \multirow{3}{*}{$\begin{array}{l}\text { Providing of information } \\
\text { about infectious diseases at } \\
\text { the facility from the facility }\end{array}$} & yes & 895 & 76.4 \\
\hline & no & 158 & 13.5 \\
\hline & unknown & 119 & 10.2 \\
\hline \multirow[t]{5}{*}{ If yes, its frequency is... } & every day & 106 & 11.8 \\
\hline & once a week & 76 & 8.5 \\
\hline & once a month & 50 & 5.6 \\
\hline & as needed & 621 & 69.4 \\
\hline & others & 42 & 4.7 \\
\hline \multirow[t]{5}{*}{ If yes, it was provided by... } & homepage & 78 & 8.7 \\
\hline & e-mail & 406 & 45.4 \\
\hline & mail & 505 & 56.4 \\
\hline & board at the facility & 204 & 22.8 \\
\hline & others & 46 & 5.1 \\
\hline \multirow{3}{*}{$\begin{array}{l}\text { Providing information about infectious } \\
\text { diseases in the community from the facility }\end{array}$} & yes & 391 & 33.4 \\
\hline & no & 338 & 28.8 \\
\hline & unknown & 443 & 37.8 \\
\hline
\end{tabular}




\section{Continued}

\begin{tabular}{|c|c|c|c|}
\hline \multirow[t]{5}{*}{ If yes, its frequency is... } & every day & 34 & 8.7 \\
\hline & once a week & 54 & 13.8 \\
\hline & once a month & 31 & 7.9 \\
\hline & as needed & 259 & 66.2 \\
\hline & others & 13 & 3.3 \\
\hline \multirow[t]{5}{*}{ If yes, it was provided by... } & homepage & 125 & 32.0 \\
\hline & e-mail & 145 & 37.1 \\
\hline & mail & 167 & 42.7 \\
\hline & board at the facility & 80 & 20.5 \\
\hline & others & 16 & 4.1 \\
\hline \multirow[t]{3}{*}{ If yes, was it useful? } & yes & 349 & 89.3 \\
\hline & no & 7 & 1.8 \\
\hline & unknown & 35 & 9.0 \\
\hline
\end{tabular}

Table 3. Estimation result of weighted logistic regression.

\begin{tabular}{|c|c|c|c|c|c|c|}
\hline & $\begin{array}{l}\text { Estimated } \\
\text { coefficient }\end{array}$ & $p$-value & $\begin{array}{l}\text { Estimated } \\
\text { coefficient }\end{array}$ & $p$-value & $\begin{array}{l}\text { Estimated } \\
\text { coefficient }\end{array}$ & $p$-value \\
\hline \multicolumn{7}{|c|}{ Dependent variable: Are you concerned about outbreaks at the facility the child attends? } \\
\hline Caregiver age & -0.081 & 0.836 & -0.050 & 0.895 & -0.052 & 0.890 \\
\hline Youngest child's age & -0.082 & 0.053 & -0.069 & 0.090 & -0.076 & 0.070 \\
\hline More than two children & -0.221 & 0.508 & -0.171 & 0.640 & -0.217 & 0.518 \\
\hline Job status & -1.847 & 0.000 & -1.831 & 0.000 & -1.829 & 0.000 \\
\hline Information provision from the facility & 0.273 & 0.447 & & & & \\
\hline (N)SASSy in the facility & & & -0.139 & 0.701 & & \\
\hline (N)SASSy at all facilities & & & & & 0.127 & 0.745 \\
\hline Constant & 4.460 & 0.000 & 4.466 & 0.000 & 4.450 & 0.000 \\
\hline \multicolumn{7}{|c|}{ Dependent variable: Are you concerned about your child's health condition? } \\
\hline Caregiver age & -0.686 & 0.042 & -0.645 & 0.059 & -0.646 & 0.058 \\
\hline Youngest child's age & -0.089 & 0.028 & -0.082 & 0.062 & -0.078 & 0.073 \\
\hline More than two children & -0.357 & 0.270 & -0.360 & 0.277 & -0.340 & 0.295 \\
\hline Job status & -0.477 & 0.120 & -0.483 & 0.108 & -0.473 & 0.120 \\
\hline Information provision from the facility & 0.354 & 0.326 & & & & \\
\hline (N)SASSy in the facility & & & 0.066 & 0.847 & & \\
\hline (N)SASSy at all facilities & & & & & 0.347 & 0.381 \\
\hline Constant & 2.815 & 0.000 & 2.851 & 0.000 & 2.774 & 0.000 \\
\hline \multicolumn{7}{|c|}{ Dependent variable: Child immunization record } \\
\hline Caregiver age & -0.070 & 0.920 & 0.018 & 0.979 & 0.042 & 0.949 \\
\hline Youngest child's age & -0.061 & 0.338 & -0.070 & 0.300 & -0.033 & 0.622 \\
\hline
\end{tabular}




\section{Continued}

\begin{tabular}{|c|c|c|c|c|c|c|}
\hline More than two children & 0.122 & 0.871 & -0.062 & 0.935 & 0.171 & 0.825 \\
\hline Job status & -0.281 & 0.659 & -0.402 & 0.552 & -0.312 & 0.633 \\
\hline Information provision from the facility & 1.372 & 0.030 & & & & \\
\hline (N)SASSy in the facility & & & 0.996 & 0.057 & & \\
\hline (N)SASSy at all facilities & & & & & 0.477 & 0.489 \\
\hline Constant & 4.127 & 0.006 & 4.401 & 0.003 & 4.167 & 0.003 \\
\hline \multicolumn{7}{|c|}{ Dependent variable: Are you concerned if your child's classmates show illness? } \\
\hline Caregiver age & -0.700 & 0.213 & -0.523 & 0.321 & -0.536 & 0.319 \\
\hline Youngest child's age & 0.021 & 0.676 & 0.024 & 0.650 & 0.067 & 0.296 \\
\hline More than two children & 1.337 & 0.012 & 1.201 & 0.021 & 1.398 & 0.011 \\
\hline Job status & -1.136 & 0.034 & -1.244 & 0.025 & -1.194 & 0.030 \\
\hline Information provision from the facility & 1.845 & 0.000 & & & & \\
\hline (N)SASSy in the facility & & & 0.748 & 0.089 & & \\
\hline (N)SASSy at all facilities & & & & & 1.064 & 0.069 \\
\hline Constant & 4.409 & 0.000 & 4.676 & 0.000 & 4.438 & 0.000 \\
\hline \multicolumn{7}{|c|}{ Dependent variable: Can you change your schedule when your child has a high fever? } \\
\hline Caregiver age & -0.068 & 0.868 & 0.020 & 0.960 & 0.033 & 0.934 \\
\hline Youngest child's age & -0.045 & 0.224 & -0.046 & 0.246 & -0.019 & 0.653 \\
\hline More than two children & 0.736 & 0.067 & 0.580 & 0.139 & 0.755 & 0.075 \\
\hline Job status & -0.065 & 0.876 & -0.214 & 0.632 & -0.151 & 0.727 \\
\hline Information provision from the facility & 1.249 & 0.001 & & & & \\
\hline$(\mathrm{N})$ SASSy in the facility & & & 0.697 & 0.046 & & \\
\hline (N)SASSy at all facilities & & & & & 0.564 & 0.298 \\
\hline Constant & 2.463 & 0.002 & 2.787 & 0.000 & 2.602 & 0.001 \\
\hline
\end{tabular}

Note: "Caregiver age" is one if the caregiver is younger than 30 years old; it is zero otherwise. "More than two children" is one if the family had more than two children; it is zero otherwise. "Job status" is one if the caregiver works outside the home; it is zero otherwise. "Information provision from the facility" is one if the attended facility provides infectious disease information to the community; it is zero otherwise. "(N)SASSy in the facility" is one if the youngest child attends an (N)SASSy activated facility; it is zero otherwise. "(N)SASSy at all facilities" is one if (N)SASSy is activated at both nursery schools and schools; it is zero otherwise. "Are you concerned about outbreaks in the facility the children attend?", "Are you concerned about your child's health condition?", "Are you concerned if your child's classmates show illness?" and "Can you change your schedule when your child has a high fever?" were one if yes; they were zero otherwise. "Children's immunization record" is one if caregivers keep child immunization record; it is zero otherwise. "Are you concerned about outbreaks in the facility the children attend?", "Are you concerned about your child's health condition?", "Are you concerned if your child's classmates show illness?" and "Can you change your schedule when your child has a high fever?" are dependent variables in logistic regression. For each dependent variable, three specifications, which include one of "Information provision from the facility" , "N)SASSy in the facility" or "(N)SASSy at all facilities", were estimated. " 0.000 " in $p$-value means less than 0.0004 . Significant coefficients were emphasized by boldface.

outbreaks is needed [2] and is used for child care. Therefore, the obtained results were consistent with those reported from earlier studies. Results also show that (N)SASSy can mitigate some difficulties of working schedule arrangements. Better information might contribute to eased absence from (nursery) schools, higher probability of visiting a doctor, and minimizing outbreak scale. In this sense, the obtained results might be consistent with those of earlier studies showing 
that $(\mathrm{N})$ SASSy activation can reduce the number of patients with some common pediatric infectious diseases [12]. However, "Information provision from the facility" apparently has a stronger effect than "(N)SASSy in the facility" or "(N)SASSy at all facilities." Results suggest that activation of (N)SASSy might not be sufficiently useful, but it might become more useful through information being delivered from the facility to caregivers.

Conversely, no significant effect of "(N)SASSy at all facilities" was found. In general, information about outbreak situations of different age classes is useful for a caregiver to take precautions. Therefore, the outbreak situation among different age classes is expected to be very useful for caregivers. Nevertheless, that expectation was not supported by estimation results.

Similarly, the youngest child's age has no significant effect on any health concern variable in any examined specification. In general, it presumed to affect caregivers' health concerns. Table 1 showed that the youngest child was younger than six years old for about half of the respondents. However, it might include a few respondents for whom the youngest children were zero-year-olds or one-year-olds because the caregivers of zero-year-olds or one-year-olds were expected to be more concerned about health. Alternatively, the youngest child's age might be multicollinearlity with other variables such as "more than two siblings" or "caregiver age."

The study described in this paper includes some limitations. First, we surveyed health concern variables as a hypothetical situation, except for vaccination records. Responses might not match the actual behavior used if the hypothetical situation is actually realized. Therefore, it is necessary to measure effects of (N)SASSy from data of actual behavior when facing outbreak information at a facility or community. That possible shortcoming remains as a challenge for future research.

A second limitation was few respondents reporting zero-year-old or one-year-old children. Data sampling was unbiased geographically and by age distribution. Therefore, few zero-year-old or one-year-old children were included. Nevertheless, children of this age group are the most vulnerable to infectious disease. For that reason, their caregivers are presumed to be more health conscious than caregivers with older children. Future studies might specifically examine caregivers with children of these ages.

A third limitation is that we cannot evaluate the ability of results to represent actual health concerns. Accumulation of data will resolve this difficulty.

\section{Conclusion}

The obtained results demonstrated that activation in (N)SASSy affects the possibility of arranging a working schedule when a child has a high fever. This capability of arranging a caregivers' working schedule might improve community health because caregiver can nurse their ill children, they can absent from (nursery) schools and then outbreak in (nursery) schools will be suppressed. This 
report is the first describing benefits of (N)SASSy from a family perspective.

\section{Acknowledgements}

This research was benefited by a Grant-in-Aid for Scientific Research (C) 15K01676 "Research for guidance and effort for introduction of (nursery) school absenteeism surveillance system" headed by Dr. Tamie Sugawara, Senior Scientist, National Institute of Infectious Diseases from Japan Society for the Promotion of Science and by a grant from the Institute for the Advancement of Woman, Tokyo Kasei University headed to Dr. Michiko Nohara.

\section{Conflicts of Interest}

The authors declare no conflicts of interest regarding the publication of this paper.

\section{References}

[1] Nohara, M. and Kato, I. (2011) Child Raising Support for Working Parents: A Follow-Up Study at a Daycare Facility. Journal of Tokyo Women's Medical University, 81, 408-415. (In Japanese)

[2] Nohara, M., Kurita, J., Sugawara, T., et al. (2018) Does Family with Children Need Information of Infectious Disease? Journal of Biosciences and Medicines, 6, 53-63. https://doi.org/10.4236/jbm.2018.612005

[3] Nohora, M., Kurita, J., Sugawara, T., et al. (2019) Providing Infectious Disease Information to Child-Rearing Families and Its Evaluation. Health, 11, 1135-1146. https://doi.org/10.4236/health.2019.119087

[4] Shimatani, N., Sugishita, Y., Sugawara, T., et al. (2015) Enhanced Surveillance for the Sports Festival in Tokyo 2013: Preparation for the Tokyo 2020 Olympic and Paralympic Games. Japanese Journal of Infectious Diseases, 68, 288-295. https://doi.org/10.7883/yoken.JJID.2014.233

[5] Matsumoto, K., Hirayama, C., Sakuma, Y., et al. (2016) Case Study of Early Detection and Intervention of Infectious Disease Outbreaks in an Institution Using Nursery School Absenteeism Surveillance Systems ((N)SASSy) of the Public Health Center. Nihon Koshu Eisei Zasshi, 63, 325-331. (In Japanese)

[6] Watanabe, M., Kurita, J., Takagi, T., et al. (2016) Early Detection and Response for Measles and Rubella Cases through the (Nursery) School Absenteeism Surveillance System in Ibaraki Prefecture. Nihon Koshu Eisei Zasshi, 63, 209-214. (In Japanese)

[7] Sugawara, T., Fujimoto, T., Ohkusa, Y., et al. (2012) The Possibility of Outbreak Control by Real-Time Surveillance with PCR Method Performed Immediately-A Case Study of Hand Foot and Mouth Disease Outbreak in a Day Care Facility for Children. Kansenshōgaku Zasshi, 86, 405-410. (In Japanese) https://doi.org/10.11150/kansenshogakuzasshi.86.405

[8] Matsumoto, K., Sugawara, T. and Ohkusa, Y. (2015) The Influenza Outbreak in 2014/2015 Season, in Sumida Ward, through the (Nursery) School Absenteeism Surveillance System. Kansenshōgaku Zasshi, 89, 748-749. (In Japanese) https://doi.org/10.11150/kansenshogakuzasshi.89.748

[9] Kurita, J., Nagasu, N., Sakurai, N., et al. (2019) Descriptive Epidemiology for Mycoplasma pneumoniae Infection Using (Nursery) School Absenteeism Surveillance 
System, and Proposal for Countermeasures. Journal of Biosciences and Medicines, 6, 33-42. https://doi.org/10.4236/jbm.2018.610005

[10] Kurita, J., Nagasu, N., Nagata, N., et al. (2018) Outbreak of Human Metapneumovirus in Ibaraki, Japan and Its Descriptive Epidemiology. Health, 10, 749-757. https://doi.org/10.4236/health.2018.106057

[11] Kurita, J., Nagasu, N., Sugawara, T. and Ohkusa, Y. (2019) Infection Control in Nursery Schools and Schools Using a School Absenteeism Surveillance System. Tohoku Journal of Experimental Medicine, 247, 173-178. https://doi.org/10.1620/tjem.247.173

[12] Kurita, J., Sugawara, T., Matsumoto, K., et al. (2018) Association among (Nursery) School Absenteeism Surveillance System and Incidence of Infectious Diseases. School Health, 14, 21-27. https://doi.org/10.1111/ped.14023

[13] Besculides, M., Heffernan, R., Mostashari, F., et al. (2005) Evaluation of School Absenteeism Data for Early Outbreak Detection, New York City. BMC Public Health, 5, 105. https://doi.org/10.1186/1471-2458-5-105

[14] Schmidt, W.P., Pebody, R. and Mangtani, P. (2010) School Absence Data for Influenza Surveillance: A Pilot Study in the United Kingdom. Eurosurveillance, 15, pii: 19467.

[15] Cheng, C.K., Cowling, B.J., Lau, E.H., et al. (2012) Electronic School Absenteeism Monitoring and Influenza Surveillance, Hong Kong. Emerging Infectious Disease, 18, 885-887. https://doi.org/10.3201/eid1805.111796

[16] Kom Mogto, C.A., De Serres, G., Douville Fradet, M., et al. (2012) School Absenteeism as an Adjunct Surveillance Indicator: Experience during the Second Wave of the 2009 H1N1 Pandemic in Quebec, Canada. PLoS ONE, 7, e34084. https://doi.org/10.1371/journal.pone.0034084

[17] Cheng, C.K.Y., Channarith, H. and Cowling, B.J. (2013) Potential Use of School Absenteeism Record for Disease Surveillance in Developing Countries, Case Study in Rural Cambodia. PLoS ONE, 8, e76859. https://doi.org/10.1371/journal.pone.0076859

[18] Fan, Y., Yang, M., Jiang, H., et al. (2014) Estimating the Effectiveness of Early Control Measures through School Absenteeism Surveillance in Observed Outbreaks at Rural Schools in Hubei, China. PLoS ONE, 9, e106856. https://doi.org/10.1371/journal.pone.0106856

[19] Aldridge, R.W., Hayward, A.C., Field, N., et al. (2016) Are School Absences Correlated with Influenza Surveillance Data in England? Results from Decipher My Data: A Research Project Conducted through Scientific Engagement with Schools. PLoS ONE, 11, e0146964. https://doi.org/10.1371/journal.pone.0146964

[20] Xu, W., Chen, T., Dong, X., et al. (2017) Outbreak Detection and Evaluation of a School-Based Influenza-Like-Illness Syndromic Surveillance in Tianjin, China. PLoS ONE, 12, e0184527. https://doi.org/10.1371/journal.pone.0184527 